\title{
Laboreal
}

Volume $9 \mathrm{~N}^{\circ} 2$ | 2013

Varia

\section{Mobilidades, territórios e serviço público : debates sobre o interesse colectivo à margem do paradigma de uma sociedade móvel}

Movilidades, territorios y servicio público : debates sobre el interés colectivo al margen del paradigma de una sociedad móvil

Mobilités, territoires et service public : débats à propos de l'intérêt collectif à la marge du paradigme d'une société mobile

Mobilities, territories and public service: debates over the collective interest at the margins of the paradigm of a mobile society

\section{Liliana Cunha}

\section{OpenEdition}

Journals

\section{Edição electrónica}

URL: http://journals.openedition.org/laboreal/5734

DOI: 10.4000/laboreal. 5734

ISSN: 1646-5237

\section{Editora}

Universidade do Porto

\section{Refêrencia eletrónica}

Liliana Cunha, « Mobilidades, territórios e serviço público : debates sobre o interesse colectivo à margem do paradigma de uma sociedade móvel », Laboreal [Online], Volume 9 №2 | 2013, posto online no dia 01 dezembro 2013, consultado o 24 setembro 2020. URL : http://

journals.openedition.org/laboreal/5734; DOI : https://doi.org/10.4000/laboreal.5734

Este documento foi criado de forma automática no dia 24 setembro 2020.

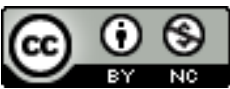

Laboreal está licenciado com uma Licença Creative Commons - Atribuição-NãoComercial 4.0 Internacional. 


\section{Mobilidades, territórios e serviço público : debates sobre o interesse colectivo à margem do paradigma de uma sociedade móvel}

Movilidades, territorios y servicio público : debates sobre el interés colectivo al margen del paradigma de una sociedad móvil

Mobilités, territoires et service public : débats à propos de l'intérêt collectif à la marge du paradigme d'une société mobile

Mobilities, territories and public service: debates over the collective interest at the margins of the paradigm of a mobile society

Liliana Cunha

\section{REFERÊNCIA}

Cunha, L. (2012). Mobilidades, territórios e serviço público : debates sobre o interesse colectivo à margem do paradigma de uma sociedade móvel. Tese apresentada para efeitos de obtenção do grau de Doutor em Psicologia. Porto : FPCE-UP.

\section{NOTA DO EDITOR}

Manuscrito recebido em : setembro/2013

Aceite após peritagem em : outubro/2013 


\section{Introdução}

1 Esta tese situa a sua análise no quadro da mobilidade por transporte público, procurando compreendê-la a partir da caracterização do sistema de transportes, das opções de organização do trabalho, do agir e do ponto de vista dos atores que a concebem (conceptores de mobilidade) e a produzem (os motoristas).

2 Enquadrada na tradição científica da ergonomia e da psicologia do trabalho da atividade, e articulada com a influência da "perspetiva ergológica", a tese discute o contributo da atividade dos motoristas, do sector dos transportes coletivos rodoviários de passageiros (transporte por autocarro), na compensação de desigualdades sociais e territoriais que os sistemas de transporte são susceptíveis de reproduzir.

3 Fundamenta-se, assim, o uso privilegiado do conceito de mobilidade ao de transporte, não raras vezes confundidos e invocados indiferenciadamente. Se o transporte é frequentemente entendido segundo uma lógica funcionalista, como a deslocação entre uma origem e um destino pré-definidos e, portanto, independente dos seus atores, o uso do conceito de mobilidade revela-a como uma produção social plural, talhada pela história (em que a atividade de trabalho de cada um também intervém), pelas características dos territórios, e pela ação pública. Neste sentido, a passagem do transporte à mobilidade, tal como aqui perspetivamos, é a manifestação da atividade humana, e mais especificamente, da atividade de trabalho. De outro modo, como poderia concretizar-se o almejado ajustamento entre a procura dos serviços de transporte público e a sua oferta, de forma tendencialmente "desencastrada" [1] das realidades concretas e sem se considerar as mediações sociais que também o determinam?

\section{2. "Ser móvel" : valor estruturante da pós-modernidade}

Os discursos sobre a sociedade contemporânea sustentam a mobilidade como um "valor dominante e transversal (...) [e com um] carácter fundamentalmente positivo" (Lannoy \& Ramadier, 2007, p.12, tradução livre), de tal forma que se fala hoje de uma 'mobilidade generalizada' (idem), ou mesmo de uma 'ideologia mobilitária' (Mincke \& Montulet, 2010), consubstanciadas pela afirmação de uma dissolução dos constrangimentos espaciais, em favor da conquista de liberdade (individual) de circulação.

Ora, se se reconhece a influência dos fenómenos de individuação na construção das sociedades contemporâneas, e de uma tendência para a instituição de formas de mobilidade com isto consonantes, as designadas 'automobilidades' (Urry, 2004), qual o espaço para uma reflexão sobre a mobilidade coletiva e para projetos de "socialização das condições de circulação" (Castells, 2000, p. 280)?

6 Ainda que hoje a mobilidade por transporte público coletivo, e mais especificamente por autocarro, seja conotada como 'pré-moderna' (ao impor limites ao projeto de uma mobilidade sem fronteiras, temporais e espaciais), comparativamente com uma mobilidade individual 'moderna' (Mom, 2009), assumimos que a sua análise e intervenção não pode ser residual, sob pena de tal contribuir para a exclusão de certas categorias da população e de certos espaços, mantidos à margem da hegemonia deste paradigma de uma "sociedade móvel". 


\subsection{Um "direito à mobilidade" consagrado}

7 Não obstante o facto de a mobilidade não ser homogénea, nem garantida para todos, em todos os lugares, o "direito à mobilidade" e, nomeadamente, à mobilidade por transporte público, é reconhecido como que uma espécie de direito 'genérico' que condiciona a efetividade da maior parte dos outros direitos" (Ascher, 2010, p. 197, tradução livre). A sua garantia é uma condição de participação na vida social, de acesso ao ensino, à saúde, ao emprego e a outras atividades e serviços, pelo que se afirma igualmente como condição de inclusão social e de cidadania, e se justifica a ação pública neste domínio.

8 Efetivamente, este direito encontra-se consagrado no Tratado que institui a Comunidade Europeia (TCE), sob a forma de uma "liberdade de circulação". Em Portugal, na Lei de Bases do Sistema de Transportes Terrestres (Lei n. 10/90, de 17 de Março), ele é expresso na "liberdade de escolha do meio de transporte, incluindo o recurso ao transporte por conta própria" e "assegurado aos utentes, em paridade de condições, igualdade de tratamento no acesso e fruição destes serviços" (artigo 2.․, n.. 2).

9 De acordo com a perspetiva ergológica, este direito enquadrar-se-ia nas "normas antecedentes" formalmente instituídas, com o propósito de regular a vida coletiva e de salvaguardar o interesse geral (Polo da Politeia), e a que estariam associados "valores sem dimensão" (Schwartz, 2000a).

10 É neste intento de garantia do interesse geral, assumindo que a oferta de serviços de transporte é suscetível de reproduzir certas desigualdades (maior oferta em lugares marcados por uma elevada densidade populacional, por exemplo), que se reconhece a atividade neste sector como de "serviço público", não sendo contudo isento o debate de valores que atravessa a evolução deste conceito e das suas práticas.

\subsection{A mobilidade como matriz institucional : o "serviço público" de transportes}

11 A tradição clássica de serviço público é frequentemente conotada com a assunção, pelo poder público, de atribuições que têm em vista a satisfação de necessidades de interesse geral (Chevallier, 1987), e que não são suscetíveis de serem satisfeitas por uma economia de mercado (Le Van-Lemesle, 2005), ou pelo menos de forma equivalente.

12 Não obstante, a entrada na década de 90 do século XX protagonizou uma crise concetual da noção de serviço público (Némery \& Routier, 1999), nomeadamente, com a privatização de alguns serviços públicos, como aconteceu no sector dos transportes rodoviários de passageiros em Portugal (Cunha \& Lacomblez, 2007; 2010; Scheller, Cunha, Nogueira \& Lacomblez, 2013). O conteúdo da noção de serviço público é hoje, talvez, menos evidente e menos consensual. Esta ideia foi amplamente corroborada por Marcello Caetano (citado por Fernandes, 1996) ao afirmar que "a expressão serviço público é ambígua quer na sua doutrina quer na prática" (p.390).

13 Segundo Dreyfus (1999), um dos fatores que terá sido determinante na crise do serviço público deve-se a "mudanças culturais e ideológicas" (p. 16, tradução livre), tributárias nomeadamente da livre concorrência, da desregulação neoliberal e do 
desmantelamento do Estado-providência. Para além das críticas sustentadas pela abordagem neoliberal que considera que o mercado pode resolver as necessidades da maior parte dos indivíduos e que, cada um, pelas suas escolhas acaba por definir as dimensões do serviço que devem ser privilegiadas pelas empresas prestatárias, a intervenção pública seria necessária apenas para facilitar o acesso ao mercado daqueles que, de outro modo, poderiam ser excluídos - por exemplo, por se encontrarem numa zona geográfica de exploração menos atrativa, ou por expressarem necessidades que não poderiam ser atendidas considerando os critérios de rentabilidade económica definidos pelo prestador do serviço. Neste sentido, assiste-se a uma retração do papel do Estado, à depreciação do sector público e à valorização do sector privado. Aliás, o Tratado que institui a Comunidade Europeia, no seu artigo 295, sustenta uma posição de "neutralidade sobre o regime de propriedade nos Estados-membros", significando isto que a Comunidade defende o tratamento igualitário das empresas encarregadas de missões de interesse geral, independentemente do seu estatuto público ou privado.

Ora, se a prestação de um serviço público, tal como é atualmente concebido, prevê a conciliação de uma orientação mercantil com uma orientação para o bem comum, como é construído um compromisso de equilíbrio numa situação em que a prestação de serviço público de transportes é, ao mesmo tempo, atravessada por situações de concorrência entre diferentes operadores [ $\left.{ }^{2}\right]$ ? Qual o seu impacto na atividade de quem presta o serviço, neste caso os motoristas?

\section{Primeiro estudo de caso : a atividade de serviço público dos motoristas numa linha explorada por diferentes operadores}

15 Um primeiro estudo de caso compreendeu a análise da atividade dos motoristas numa linha urbana, cujo traçado se situa na periferia do centro urbano do Porto. Trata-se de uma linha cuja exploração é partilhada por três operadores distintos, dois dos quais privados e um público (o traçado da linha é, sobretudo, comum aos dois operadores privados - a origem, o destino e as paragens são inclusivamente comuns - percorrendo o operador público cerca de metade do percurso, de forma partilhada com estes operadores).

16 A análise da atividade foi desenvolvida em dois momentos, correspondentes a fases distintas da história de exploração desta linha de autocarro. Os objetivos inerentes à exploração do percurso por cada um dos operadores eram, no primeiro momento (de novembro de 2003 a abril de 2004), claramente diferenciados, sendo que a nossa análise recaiu, sobretudo, num dos operadores privados, a quem foi atribuída uma missão de serviço público, em resultado de um "acordo de exploração" estabelecido com o operador público (Cunha \& Lacomblez, 2006). De forma sucinta, podemos assim definir a prioridade de cada um dos operadores : prestar um serviço público de transportes (operador público); cumprir o "acordo de exploração", definido com base no pagamento de um valor $/ \mathrm{km}$ percorrido e, por conseguinte, percorrer o número de quilómetros previsto, no horário prescrito (operador privado com acordo de exploração); e transportar o maior número possível de passageiros, uma vez que a receita alcançada provinha da venda de bilhetes (segundo operador privado). 
17 As observações em contexto real revelaram que, em lugar da competitividade a que à partida poderíamos pensar que conduziria esta situação de co-atividade (uma mesma linha e horários muito próximos), foram identificadas estratégias que correspondem a compromissos coletivamente construídos e validados. Uma dessas estratégias, por exemplo, consistia em permitir que os motoristas do segundo operador privado iniciassem a atividade sempre alguns minutos mais cedo, ganhando vantagem relativamente aos motoristas das duas outras empresas, pela oportunidade de transportarem mais passageiros e de gerarem mais receita, tal como preconizavam os objetivos definidos para a sua atividade. Os outros motoristas facilitavam inclusivamente a concretização deste objetivo, procurando não os ultrapassar quando deles se aproximavam ou permitindo-lhes a ultrapassagem, para que continuassem a seguir à frente no percurso.

18 A essência deste compromisso construiu-se na história desta exploração partilhada, e manteve-se porque os objetivos associados à atividade dos motoristas de cada uma das empresas, por não serem incompatíveis nem concorrentes, o permitiam. Esta situação torna visível uma negociação partilhada no seio do que a perspetiva ergológica define como "entidades coletivas relativamente pertinentes" (ECRP) (Schwartz \& Durrive, 2003). A configuração destas ECRP é espontânea, a sua circunscrição é fluida, e vulnerável às mudanças que vão sendo introduzidas nos contextos de trabalho. Não obstante, elas constituem-se sob a alçada de valores partilhados e sob o objetivo de regulação da "vivência em comum" no percurso, que se traduz também numa melhoria do serviço de transportes prestado. De facto, se os motoristas tinham horários prescritos muito semelhantes entre si, os clientes aparentemente perdiam a vantagem de terem duas ou três alternativas de transporte para o mesmo destino. $O$ desfasamento de horários entre os autocarros das três empresas que se procurava introduzir em contexto real, pelas estratégias coletivas desenvolvidas pelos motoristas, correspondia a um escalonamento da passagem dos autocarros e, consequentemente, à oferta de uma maior frequência de transporte.

19 O regresso ao terreno, num segundo momento (de maio de 2007 a Fevereiro de 2008), teve lugar numa fase de mudança na exploração desta linha - mostrando que as normas antecedentes não são intemporais, mesmo se reclamam sempre uma antecipação do agir -, ainda que o traçado do percurso não tenha sofrido alterações, e se tenham mantido os mesmos operadores responsáveis pela sua exploração. Para além das mudanças no sistema global de transportes na área metropolitana do Porto, na sequência da integração do metro na rede, que tiveram o seu impacto na bilhética [ $\left.{ }^{3}\right]$, as condições estabelecidas no "acordo de exploração", entre o operador público e o operador privado cuja atividade analisámos de forma mais sistemática, também sofreram alterações. 0 regime de compensação deste operador privado, pela assunção de obrigações de serviço público, passou a ser a aquisição de direitos sobre a receita obtida. Sabendo que há sempre reverberações entre normas antecedentes e atividade, que debate de normas protagoniza atualmente a atividade dos motoristas neste contexto?

Com esta mudança, os objetivos dos dois operadores privados passaram a ser concorrentes. As entrevistas conduzidas com os motoristas do operador privado em análise, revelaram que novas opções de organização do trabalho foram definidas, apesar de a missão de serviço público atribuída não o prever. Os horários foram alterados, procurando garantir vantagem na circulação relativamente ao segundo 
operador privado, o que acabou por confrontar os motoristas com um conflito na "escolha" do horário a cumprir (o horário definido pela empresa, ou o horário divulgado aos clientes ?) ; foi feita uma seleção dos motoristas para esta linha, entre outras estratégias que acabaram por fomentar a concorrência entre os motoristas das duas empresas. A atividade é, desde então, vivida de uma forma dramática e fonte de sofrimento : pela competitividade que comprometeu a preservação deste "coletivo" (um coletivo não predefinido, mas constituído pela atividade, num determinado momento) ; por só se "trabalhar para a gaveta" (ênfase nas situações de concorrência e nas inflexões de orientação mercantil) ; e pela ameaça a uma pedagogia sobre o que os clientes podem esperar/exigir de um serviço público de transportes.

21 A análise desta atividade de serviço público torna visíveis diferentes injunções contraditórias que se impõe (re)conhecer. A ênfase no cumprimento das obrigações inerentes à noção de serviço público não é, por si só, suficiente ; é necessário considerar em que medida as opções de organização do trabalho definidas sob a alçada de tal estatuto, o favorecem ou, pelo contrário, exigem que os trabalhadores façam arbitragens entre o interesse da própria empresa e o interesse público (Linhart, 2009). Dito de outra forma, se se assume um princípio de neutralidade relativamente ao estatuto das empresas prestatárias de serviço público, esse princípio não pode escamotear o questionamento das condições em que ele é co-produzido pelos atores envolvidos, e o seu impacto na saúde daqueles que o prestam.

\section{Que custos inerentes à evolução da concetualização do serviço público?}

Para dar resposta a esta questão, foi adotada uma abordagem metodológica de cariz quantitativo, conduzida a partir da aplicação do Inquérito Saúde e Trabalho (BarrosDuarte, Cunha \& Lacomblez, 2007) a uma amostra de 161 motoristas, entre os quais 158 homens e 3 mulheres, integrados em cinco empresas, sendo uma do setor público (90 motoristas da amostra total) e as restantes quatro empresas do setor privado (71 motoristas da amostra total), com o objetivo de analisar a sua perceção face às condições em que exercem a atividade de trabalho e os seus efeitos ao nível da saúde.

Os constrangimentos relativos ao prolongamento da jornada de trabalho são identificados por quase todos os trabalhadores participantes (82 motoristas - $91.1 \%$, na empresa pública ; 69 motoristas - 97.2\%, nas empresas privadas). Mas, apesar de não serem significativas as diferenças neste item relativamente ao tipo de empresa, os motoristas das empresas privadas declaram, quase quatro vezes mais $(\mathrm{OR}=3.50)[4]$, ultrapassar o horário normal de trabalho, comparativamente com os motoristas da empresa pública. Esta constitui, aliás, uma das principais queixas destes trabalhadores, expressando a tendência das empresas privadas para diminuir o tempo prescrito de realização dos percursos, tornando-o, frequentemente, muito desfasado face às necessidades reais.

Não obstante, estes resultados poderão parecer à partida paradoxais com os que apontam para o facto de os motoristas das empresas privadas da nossa amostra revelarem, com cerca de sete vezes mais probabilidade do que os motoristas da empresa pública, que na gestão da sua atividade influenciam o ritmo ou velocidade do trabalho (OR $=7.35$ ), e que tomam decisões por si mesmos. Tal é visível, nomeadamente, quando aceleram ou atrasam a circulação no percurso, em função da distância a que se 
encontram dos motoristas de outras empresas que exploram a mesma linha. Num contexto em que a prestação de serviço público é atravessada por situações de concorrência, preservar "a boa distância" constitui a prioridade dos motoristas, ou seja, "não andar colado" aos motoristas de outras empresas que partilham um mesmo percurso, porque tal equivale a um serviço "perdido" (possibilidade de não se transportar passageiros nessa viagem).

Isto significa que a maior liberdade de que aparentemente dispõem os motoristas das empresas privadas para gerir a sua atividade de serviço público, lhes é concedida em prol da prossecução de objetivos de rentabilidade. E, face a uma deficiente regulação do serviço prestado, é transferida para estes trabalhadores a responsabilidade de fazerem opções, que requerem um uso de si (Schwartz, 2000b), na tentativa de satisfazer o interesse da própria empresa, sem comprometer a qualidade do serviço prestado ao cliente (Orban, 2004).

Mas, nem sempre estas tentativas se revestem de sucesso. Um exemplo disso é o facto destes motoristas referirem estar expostos ao risco de agressão verbal, com uma probabilidade cerca de 15 vezes superior $(\mathrm{OR}=14.72)$ aos motoristas da empresa pública.

Não se trata, obviamente, tal como referem Schwartz e Durrive (2003), de sustentar aqui a eliminação dos valores mercantis, mas de considerar os custos das tentativas de reequilíbrio das habituais relações de subordinação entre diferentes valores na atividade.

\section{Segundo estudo de caso : conceção de uma rede de transportes e atividade dos motoristas num contexto predominantemente rural}

28 Falar dos custos inerentes à evolução da noção de serviço público, a partir de uma análise baseada numa comparação entre o "público" e o "privado" correria o risco de nos levar a uma aporia (Orban, 2004). É imperativo ter em conta igualmente outras categorias de análise, na reflexão sobre os custos individuais e coletivos da evolução da noção de serviço público.

29 Exemplo disso é o conceito de território, frequentemente desconsiderado nos discursos sobre a mobilidade, apesar de ser um elemento diferenciador das formas de mobilidade produzidas.

nosso segundo estudo de caso foi desenvolvido no âmbito do projeto de reconcepção da rede de transportes públicos por autocarro de uma área concelhia da região Centro de Portugal, tipificada como "predominantemente rural" (INE, 2009). O pedido de intervenção, relativo à reconcepção da rede de transportes por autocarro, foi protagonizado pela empresa privada detentora do monopólio de concessões de exploração no concelho, em articulação com a Câmara Municipal (responsável pelo pagamento de "indemnizações compensatórias", pela prestação de serviço público de transportes no município); e dirigido a uma equipa de conceptores de mobilidade (constituída, sobretudo, por engenheiros, mas também por geógrafos e matemáticos).

31 O território em análise compreende uma vasta área, apresentando um nível de densidade populacional considerado baixo (aproximadamente $40 \mathrm{Hab} / \mathrm{Km}^{2}$ ), o que 
constitui um constrangimento importante numa intervenção com o objetivo de melhorar as condições de mobilidade e assegurar a viabilidade económica dos serviços prestados. Neste caso concreto, torna-se visível o dimensionamento de valores do bem comum, traduzido no facto de a garantia do direito à mobilidade ocorrer de forma privilegiada em lugares onde a operacionalização desse direito pode ser conciliada com a sustentabilidade económica dos serviços prestados, ou seja, lugares onde se regista uma maior procura. E isto mesmo quando se define como obrigatória a prestação de serviços de transporte, como é caso do transporte por motivo escolar (Decreto-Lei no 299/84, de 5 de Setembro). Foi, aliás, por este motivo que no projeto de reconceção da rede de mobilidade se teve particularmente em atenção as necessidades dos estudantes, uma vez que são eles os principais utilizadores do transporte público e os que mantêm, ao longo do ano, um padrão de utilização regular.

Em termos metodológicos, foram realizadas observações da atividade dos conceptores e dos motoristas, em contexto real e em cada uma das linhas que compõem a rede, complementadas com entrevistas sobre as necessidades concretas a que, do seu ponto de vista, o projeto da nova rede deveria ser capaz de responder.

Antes da intervenção, a oferta de serviços de transporte público era limitada a apenas duas viagens (uma viagem de manhã e a outra na hora de ponta da tarde) ; ao período escolar; e aos dias úteis.

Os resultados obtidos tornaram visível a inexistência de um espaço partilhado para o debate, entre conceptores e motoristas, sobre a atividade concreta destes, as suas condições de trabalho, as dificuldades e as estratégias que desenvolvem para as contornar, e os compromissos que têm que construir para garantir o transporte aos que se encontram mais afastados dos locais de circulação do autocarro. Na perspetiva dos motoristas, nem sempre seriam, por isso, sustentadas as decisões de "corte" de alguns lugares no traçado dos percursos, tendo como referência "contagens" do número de passageiros, considerando que estas foram realizadas de forma não continuada no tempo. Os conceptores, por sua vez, assumem as variações relativas ao que habitualmente acontece, ou ao que está prescrito, como "irregularidades", mesmo se constituem alternativas indispensáveis para dar resposta às necessidades dos utilizadores e, de forma mais global, para preservar o direito à mobilidade de uma parte da população. Tal é o caso, por exemplo, da realização de mais paragens do que as previstas, ou da introdução de desvios relativamente ao traçado definido, para transportar os que se encontram mais afastados e, por conseguinte, da antecipação dos horários de início dos percursos, garantindo que apesar destes desvios, os horários do autocarro são compatíveis com os horários escolares.

Se os transportes públicos são assegurados num espaço delimitado, com base na intencionalidade de quem define o seu traçado, ao mesmo tempo, a atividade concreta e quotidiana nesse espaço vai atualizando-o - dando resposta a necessidades específicas, como fazer paragem num lugar antes não previsto e investindo as relações nesse espaço de outros valores. Ainda assim, apesar de o contributo dos motoristas ser indispensável na resposta a necessidades que o sistema de mobilidade não é capaz de satisfazer, eles surgem neste projeto de reconceção mais como “(...) objeto de estudo (...) [do que] como protagonistas do trabalho de pesquisa" (Clot, 1981, tradução livre).

36 Não foram, contudo, objeto de estudo as suas condições de trabalho e de emprego, entendidas como uma questão extrínseca ao projeto, apesar de a melhoria das condições de mobilidade advir também de um potencial introduzido pela atividade 
destes trabalhadores. Num contexto pouco densificado como este, a situação de emprego dos motoristas é marcada pela precariedade dos contratos de trabalho, frequentemente a tempo parcial, em virtude do funcionamento da rede limitado a duas circulações diárias, em cada linha, e ao período escolar. Não deixa, portanto, de se perpetuar em silêncio a desigualdade das suas condições de trabalho e de emprego, comparativamente com os que exercem a mesma atividade em territórios considerados mais atrativos...

\section{Conclusões}

A tensão entre o "conceito" de serviço público e a "realidade" patente nos resultados apresentados, tornou visível como o debate sobre este conceito estruturante na vida coletiva, não poderá continuar a circunscrever-se aos princípios que conceptualmente lhe são intrínsecos, mantendo na penumbra a forma como ele é concretamente concebido e organizado para responder às necessidades que estão na sua origem. E se esta é uma questão emergente a que se impõe dar resposta, sabemos também que ela ultrapassa os limites deste estudo. As condições de trabalho associadas à prestação de um serviço público e as opções de organização do trabalho que o configuram são, afinal, um problema de sociedade. $O$ contributo que esta tese traduz é o de sustentar uma maior atenção aos conflitos que a evolução das normas que regulam a sua prestação acabou por entrever, abrindo caminho em algumas situações para uma usurpação dos valores que lhe são identitários (Linhart, 2009). A não convocação do ponto de vista do trabalho, ancorado nas suas especificidades territoriais, torna ilusória a ideia de que é possível definir "boas práticas" em termos de políticas de mobilidade, concebidas em desaderência, e por isso universais e transferíveis. Como garantir, então, o direito à mobilidade e o direito ao território?

E se é de direitos que falamos, não deixa de ser paradoxal o facto de em Portugal, os motoristas, neste caso do sector público, terem visto recentemente decretada a perda do direito ao transporte gratuito (no caso específico dos trabalhadores reformados, e preconizada a sua limitação para os trabalhadores ativos), quando tal regalia foi atribuída em substituição de aumentos salariais. É preciso pois que o espaço público onde exercem a sua atividade seja também palco de discussão sobre o desmantelamento deste direito, na expectativa de que a atual conjuntura não contenha a mobilização para o fazer...

\section{BIBLIOGRAFIA}

Ascher, F. (2010). Les nouveaux principes de l'urbanisme. La Tour d'Aigues, France : Éditions de l'Aube.

Barros-Duarte, C., Cunha, L., \& Lacomblez, M. (2007). INSAT : uma proposta metodológica para análise dos efeitos das condições de trabalho sobre a saúde, Laboreal, 3(2), 54-62. 
Castells, M. (2000). A questão urbana (A. Caetano Trad.). São Paulo, Brasil : Edições Paz e Terra.

Chevallier, J. (1987). Le service public. Paris, France : PUF.

Clot, Y. (1981). Présentation. In I. Oddone, A. Re \& G. Briante (Eds.), Redécouvrir l'expérience ouvrière. Vers une autre psychologie du travail ? (I. Barsotti \& M.-L. Barsotti Trad.) (pp. 7-13). Paris : Éd. Sociales.

Commission des Communautés Européennes (2000). Règlement du Parlement Européen et du Conseil relatif à l'action des États membres en matière d'exigence de service public et à l'attribution de contrats de service public dans le domaine des transports de voyageurs par chemin de fer, par route et par voie navigable, COM(2000) 7 final. Bruxelles, 26.7.2000.

Cunha, L., \& Lacomblez, M. (2006). Mudanças no sector dos transportes em Portugal : que caminhos para a actividade de serviço público e para a preservação do interesse geral ? Laboreal, 2, (2), 26-37. http://laboreal.up.pt/revista/artigo.php?id=37t45nSU54711227854127:811

Cunha, L., \& Lacomblez, M. (2007). Market and regulation of general interest in the passenger land transport sector: a debate renewed by drivers' activity. @ctivités, 4 (1), pp. 141-148, http:// www.activites.org/v4n1/v4n1.pdf

Cunha, L., \& Lacomblez, M. (2010). La production d'un service public : ce que révèle l'activité de conducteurs de bus au Portugal. In H. Maksim, S. Vincent, C. Gallez \& V. Kaufmann (Dir.). L'action publique face à la mobilité (pp. 51-75). Paris : Éditions L'Harmattan.

Derrienic, F., Saurel-Cubizolles, M.-J., \& Monfort, C. (2003). Santé, conditions de travail et cessation d'activité des salariés âgés. Travail et Emploi, 96, 37-53.

Dreyfus, J-D. (1999). Service public et secteur public : association ou dissociation? In H. Groud (Ed.), Mutations du service public et territoires, (pp. 11-18). Paris, France : Éditions L’Hartmattan. Fernandes, J. (1996). Dicionário jurídico da Administração Pública. Lisboa, Portugal : Almedina. Guèrin, F., Laville, A., Daniellou, F., Duraffourg, J., \& Kerguelen, A. (1991). Comprendre le travail pour le transformer. Paris, France : Éditions ANACT.

Instituto Nacional de Estatística (INE) (2009). Tipologia de áreas urbanas. Retirado de www.ine.pt Lannoy, P., \& Ramadier, T. (Eds.) (2007). La mobilité généralisée. Formes et valeurs de la mobilité quotidienne. Louvain-la-Neuve, Belgique : Academia Bruylant.

Le Van-Lemesle, L. (2005). Cauwès et Colson, le juriste et l'ingénieur : une ou deux conceptions du service public ? Revue d'histoire moderne et contemporaine, 3 (52-53), 75-87.

Linhart, D. (2009). Comment l'entreprise usurpe les valeurs du service public. Le Monde diplomatique, 666, 20.

Mincke, C., \& Montulet, B. (2010). L'idéologie mobilitaire, Politique, 64. Retirado de http:// politique.eu.org

Mom, G. (2009). Inventer et établir l'Histoire de la mobilité : aux origines d'un changement de paradigme. In M. Flonneau \& V. Guigueno (Eds.), De l'histoire des transports à l'histoire de la mobilité ? (pp. 25-39). Rennes, France : Presses Universitaires de Rennes.

Némery, J.-C., \& Routier, J.-C. (1999). Avant-propos. In H. Groud (Ed.), Mutations du service public et territoires, (pp. 7-10). Paris, France : L'Hartmattan.

Orban, E. (2004). Service public! Individu, marché et intérêt public. Paris, France : Éditions Syllepse. 
Scheller, L., Cunha, L., Nogueira, S., \& Lacomblez, M. (2013). Le temps des conductrices de bus en France et au Portugal. Travail, genre et sociétés, n.․ 29, 69-86.

Schwartz, Y. (2000a). Le paradigme ergologique ou un métier de philosophe. Toulouse, France : Octarès Éditions.

Schwartz, Y. (2000b). Trabalho e uso de si. Pró-posições, 1, 5 (32), 34-50.

Schwartz, Y., \& Durrive, L. (Eds.) (2003). Travail \& Ergologie. Entretiens sur l'activité humaine. Toulouse, France : Octarès Éditions.

Steiner, P. (2007). La sociologie économique. Paris, France : Éditions La Découverte.

Urry, J. (2004). The ‘System' of Automobility. Theory, Culture \& Society, 21, 25-39.

\section{NOTAS}

1. O "encastramento" é uma noção desenvolvida por Karl Polanyi e retomada pela "nova sociologia económica" (Steiner, 2007), que sustenta a compreensão dos fatores sociais que suportam o funcionamento das economias de mercado, assumindo que o económico está encastrado no social.

2. Ainda que na tradição da ergonomia e da psicologia do trabalho da atividade seja comum a utilização deste termo para designar "toda a pessoa que exerce uma atividade profissional, quaisquer que sejam as suas características" (Guèrin, Laville, Daniellou, Duraffourg \& Kerguelen, 1991, p.15, tradução livre), mantemos aqui o uso deste conceito, uma vez que faz parte da "linguagem operativa" no sector de atividade em análise. O significado que lhe é atribuído neste contexto particular, e que aqui adoptamos, corresponde a uma empresa de direito público ou privado a quem é atribuída a responsabilidade pela prestação de serviços de transporte público de passageiros, em zonas concessionadas de exploração de linhas, por um poder público central ou local (Commission des Communautés Européennes, 2000).

3. A bilhética e tarifário das três empresas sofreram também mudanças, sendo igual para os três operadores, que passaram a partilhar o sistema "Andante". Neste sentido, o cliente pode entrar sempre no primeiro autocarro, independentemente da empresa de transportes em questão.

4. $O$ odds ratio (OR) é uma medida do risco relativo de se estar exposto a determinada situação de trabalho, para um dado fator ou grupo (p.e., ser motorista numa empresa privada), comparativamente com a classe de referência definida (ser motorista numa empresa pública). Se $\mathrm{OR}>1$, dizemos que o fator associado constitui um risco possível de exposição, enquanto que no caso contrário, $\mathrm{OR}<1$, o fator pode ser protetor perante a exposição (Derrienic, Saurel-Cubizolles \& Monfort, 2003).

\section{AUTOR}

\section{LILIANA CUNHA}

Centro de Psicologia da Universidade do Porto, Centro de Estudos em Desenvolvimento Humano, Faculdade de Educação e Psicologia, Centro Regional do Porto da Universidade Católica 
Portuguesa, Rua Diogo Botelho, 1327 , 4169-004 Porto

lcunha@porto.ucp.pt 